\title{
Photography and the Visual Particularities of Young People on the Autism Spectrum
}

\author{
USCHI KLEIN, University of Brighton
}

\begin{abstract}
Photographs are created, recreated and shared extensively and repeatedly, suggesting that people have little choice but to look at them. Nonetheless, the diverse ways of seeing in contemporary visual culture entail different visions, experiences and practices of visuality. This article suggests autistic people approach photography in their own ways to visually express their everyday lives. While sensory experiences differ in autistic individuals, they appear to embody visuality with their sensory modalities, using primarily their vision, but also their kinaesthetic experience and proprioceptive awareness to photograph the world around them.

Drawing from findings from an empirical study on the photographic practices of young people on the autism spectrum, this paper discusses how two participants use photography to capture the ways they see the world. Photography provides a context in which individuals can illustrate their visual experiences, and specific and diverse social and personal realities. The medium encourages them to make, use and discuss their own photographs, which, in turn, generates thoughts of lived experiences on which they may otherwise never reflect. While offering new insights into how photography mediates autistic individuals' sensory perceptions of their visual world, this paper will further consider the contributions photography makes to the everyday lives of autistic people.
\end{abstract}

\section{KEYWORDS}

Autism Spectrum Conditions; Digital Photography; Visual Culture; Visual Experience; Visuality 


\section{Introduction}

The ubiquity of photographs in contemporary visual culture implies that people consume, reproduce and distribute images of their everyday lives routinely and widely (Frosh 2003). Frequently taken on camera phones, photographs circulate in a variety of contexts with no single, intrinsic meaning attached to them. Indeed, photography affords people the opportunity to navigate images through their social worlds, record the eventful and the mundane, influence conversations and inspire imaginations (Lee 2010). As a cultural form and social practice, photography is complex and cannot be linked to just one cultural meaning, visual experience or consistent practice (Hand 2012; Larsen and Sandbye 2014). There are many ways people use photography, and multiple approaches to reading, interpreting and understanding photographs (Harper 2002; Rose 2012). Within the scholarships of visual culture and photography, however, little attention has been paid to the photography of autistic people. Given the recognition of sensory perceptual differences in autism, this is rather surprising. More precisely, studies on sensory perceptual experiences reveal that autistic people have an ability to focus their vision on details, enabling them to notice small changes in their familiar surroundings; they also appear to rely on their awareness of body position and movement to make sense of their environment (Bogdashina 2003; Boucher 2009; Garner and Hamilton 2001; Grandin 2006). While that often occurs at the expense of seeing and experiencing the whole scene or object, this study suggests that participants appear to embody visuality, using vision, kinaesthetic experience and proprioceptive awareness to photograph the world around them.

As a point of departure, this paper follows Joyce Davidson's view that autistic experiences in perception 'tend to involve other ways of being-in-the-world, separate senses of selves and space that give rise to distinctive cultural experiences, and so also, cultural expression' (2008, 793, italics in original). The prevailing diagnosis of autism lists a triad of impairments, also described as a 'profile of abilities' (Attwood 2007,271 ) in the areas of social interaction, language and patterns of behaviour, interests and activities. Studies and autobiographies also reveal that unusual responses to sensory stimuli are seen as core features of autism (Attwood 2007; Bogdashina 2003; Boucher 2009; Grandin 2006). This paper focuses on the visual and perceptual differences of autism that manifest themselves in relation to photography; however, an in-depth analysis of autism is beyond the scope of this paper.

Drawing on empirical research evidence from young autistic people aged 18 to 27, this paper suggests that participants approach photography in their own ways to express their visuality and diverse social and personal realities of 'being-in-the-world' (Heidegger 1962). This understanding developed through adopting a multi-method approach to ensure topics relevant to participants remained central (Clark-Ibanez 2007). Considering the use of photographs as visual stimuli to acquire information, photo elicitation was nevertheless the main visual method used, as it encouraged participants to speak more freely about their own images, and a very productive way of discussing the meaning and intentions participants had in relation to their own photographs (Harper 2002; Joanou 2009; Packard 2008; Prosser 2011).

This paper is therefore organised in three parts. Part I discusses the concept of seeing; Part II includes the study design, a critical overview of the visual approaches that this study draws on, and two case studies that describe the photographic practices and 
images of two autistic participants. Following the vignettes, Part III discusses theories that underpin this study, including a discourse on phenomenology and embodiment (Bakhtin 1993; Merleau-Ponty 1962; Noland 2009).

\section{The Subjectivity of Seeing and Perception through Photographs}

It is widely argued that digital photographs circulate in a variety of contexts with no single, intrinsic meaning attached to them (Hand 2012). Jon Prosser suggests that the explosion of visual images appears to presuppose notions that 'we have no choice but to look' $(2011,479)$, that seeing is taken for granted, and that people are visually literate (Berger 1992; Schwartz 2007). There are different ways of seeing and perceiving, and several contexts in which photography can be used. The medium facilitates an individual's perception and experience of being in the world, as photographs have the power to capture and freeze an image, a moment in time.

Both participants illustrate their different ways of seeing through their photographs. For example, Joe only sees the kingfishers in Figure 1 as the minute detail he wanted to capture, with the rest being unimportant, whereas Alex produces close-up shots of the details he wanted to portray (see Figures $4 \& 5$ ).

The idea of linking seeing with the production of photographs is reinforced by Donna Haraway who argues:

The "eyes" made available in modern technological sciences shatter any idea of passive vision; these prosthetic devices show us that all eyes, including our own organic ones, are active perceptual systems, building in translations and specific ways of seeing, that is, ways of life. There is no unmediated photograph or passive camera obscura in scientific accounts of bodies and machines; there are only highly specific visual possibilities, each with a wonderfully detailed, active, partial way of organizing worlds (1991, 190, italics in original).

While the proliferation of images in contemporary visual culture signifies an infinite mobility and interchangeability of photographs, Haraway's attention on the visual technologies that facilitate people's ways of seeing suggest that images are complex and denote specificity and distinctiveness. Haraway further stresses that they convey the idea of 'the loving care people might take to learn how to see faithfully from another's point of view, even when the other is our own machine' (ibid.). This is particularly true for Joe, when he referred to a frog image that he showed me.

Questioning the power of photographs, their truth value and the subjectivity of the photographer, Susan Sontag proposes that,

The photographer was thought to be an acute but non-interfering observer - a scribe, not a poet. But as people quickly discovered that nobody takes the same picture of the same thing, the supposition that cameras furnish an impersonal, objective image yielded to the fact that photographs are evidence not only of what is there but of what an individual sees, not just a record but an evaluation of the world $(1977,88)$. 
Here, Sontag implies that photographs do not copy but construct reality, which in turn enables photographers to find their subjective truths in photographs. Debates on the truth value of the photograph date back to the medium's invention in 1839 , and still continue after the arrival of digital technologies. Considering the photography of Joe and Alex, they either appear to perceive photographs as a true, accurate record of what was there when the shutter was pressed (Barthes 2000), or as a construction of visual communication, respectively. To illustrate this, Joe respects his photographs in their original state without manipulating them, whilst Alex enhances his images to express his visual particularities of his everyday life. Nevertheless, despite their different approaches to photography, they both appear to embody visuality, using vision, kinaesthetic experience and proprioceptive awareness to photograph their everyday lives.

\section{Study Design}

Following my volunteering involvement with autistic young people to advance my understanding of the condition, I developed the methodology of this study by initially drawing on my experience and the literature on studies with vulnerable young people (e.g. Aldridge 2007; Joanou 2009). Once the four participants were recruited for this study (three male and one female with high-functioning autism/Asperger syndrome aged 18 to 27), the methodology was further tailored in line with participants' abilities, interest and skills (Packard 2008; Tinkler 2008; Yates 2010). This was paramount and aimed to 'establish a rapport, prompt for further responses and be as unobtrusive as possible' (Aldridge 2007, 4); it further encouraged reflexivity in the research process and helped develop a more profound understanding of photography and autism.

After obtaining ethical approval, the study involved three stages that were carried out over nine months; (1) an initial one-hour meeting informed individuals about the nature of the study, and included a semi-structured interview; (2) between four and seven one-hour sessions took place in which the technique of photo elicitation was mostly used to discuss participants' own photography; (3) a follow-up meeting with individuals included a semi-structured interview to discuss participants' photography after their involvement in the study.

Verbal and written informed consent was first sought at the start of the study; however, participants were reminded during each session that they could revisit and change their decisions anytime, particularly regarding their participation and images.

\section{Participatory Visual Methods}

The scholarship on visual methodologies and participatory visual research methods includes fields of interdisciplinary knowledge and practice that are informed by a range of approaches across the arts, humanities and social sciences (Guillemin and Drew 2010, 175; Mitchell 2011; Pink 2009; Rose 2012). A leading scholar in the area of participatory visual research is Sarah Pink who stresses that in the current visual research environment, photographs play a crucial role in 'how we experience, learn and know as well as how we communicate and represent knowledge' $(2013,1)$, 
further arguing that "visual research must also accommodate embodiment and the senses' (ibid., 3). Elsewhere Pink reinforces that 'sensoriality is fundamental to how we learn about, understand and represent other people's lives' $(2009,7)$. Indeed, the relationship between senses, lived experiences and photographs is imperative in this study; without participants' self-reflexive involvement in discussing their own photographs, it would be difficult to understand their subjective perspectives and interpretations. Moreover, considering autistic people's distinct sensory approach to their photography, employing a multimodal ethnographic approach for this study is a suitable way of exploring and understanding their photography, in particular because,

[E]thnographic strategies are also shaped by the subjects' situation, their global as well as local perceptions, and their demands and expectations of us [the researchers]. There can be no blueprint for how to do fieldwork. It really depends on the local people (Josephides 1997, 32).

With a focus on vision, photo elicitation is one productive approach of interviewing participants to discuss the meaning and intentions of their own photographs (I would have otherwise never seen the two kingfishers in Joe's photograph). As various participatory studies suggest, however, photo elicitation alone is not researcher-proof and should be used in combination with other research methods (Aldridge 2007; Harper 2002; Joanou 2009; Packard 2008). More precisely, developing a flexible and inclusive methodological approach to carry out this study facilitates the active engagement of participants to share their lived experiences, perspectives, insights and knowledge in relation to their photography.

Once the visual data has been collected, a productive way of analysing visual material is Gillian Rose's approach to 'critical visual methodology'. She offers a theoretical framework for exploring the meaning of 'visual materials in terms of three sites: the site of production [...]; the site of the image itself [...]; and the site [...] of its audience' (2012, 19, italics in original). Given the complexity of her approach to think about (1) where an image is made; (2) how to interpret its visual content; and (3) how to examine the effects and meanings images have on audiences, this theoretical framework is useful for analysing participants' photographs.

In conclusion, this brief analysis on participatory visual methods aimed to develop an understanding of the field, and further demonstrate the importance of drawing on a number of research methods, theoretical frameworks and analytical approaches in order to carry out research in a more forward-looking, integrated and profound way.

\section{Case Studies}

\section{The 'Specific Area in that Photo': An Introduction to Joe's Photography'}

Joe was 27 when he took part in the study. A quiet individual on the autism spectrum, he is an artist with a focus on sculpture and painting. Enjoying being outdoors and learning about flora and fauna, he also volunteers as a ranger at a countryside centre, a

\footnotetext{
${ }^{1}$ Subsequent quotes under this subheading are from the same research participant, Joe D., except where otherwise specified.
} 


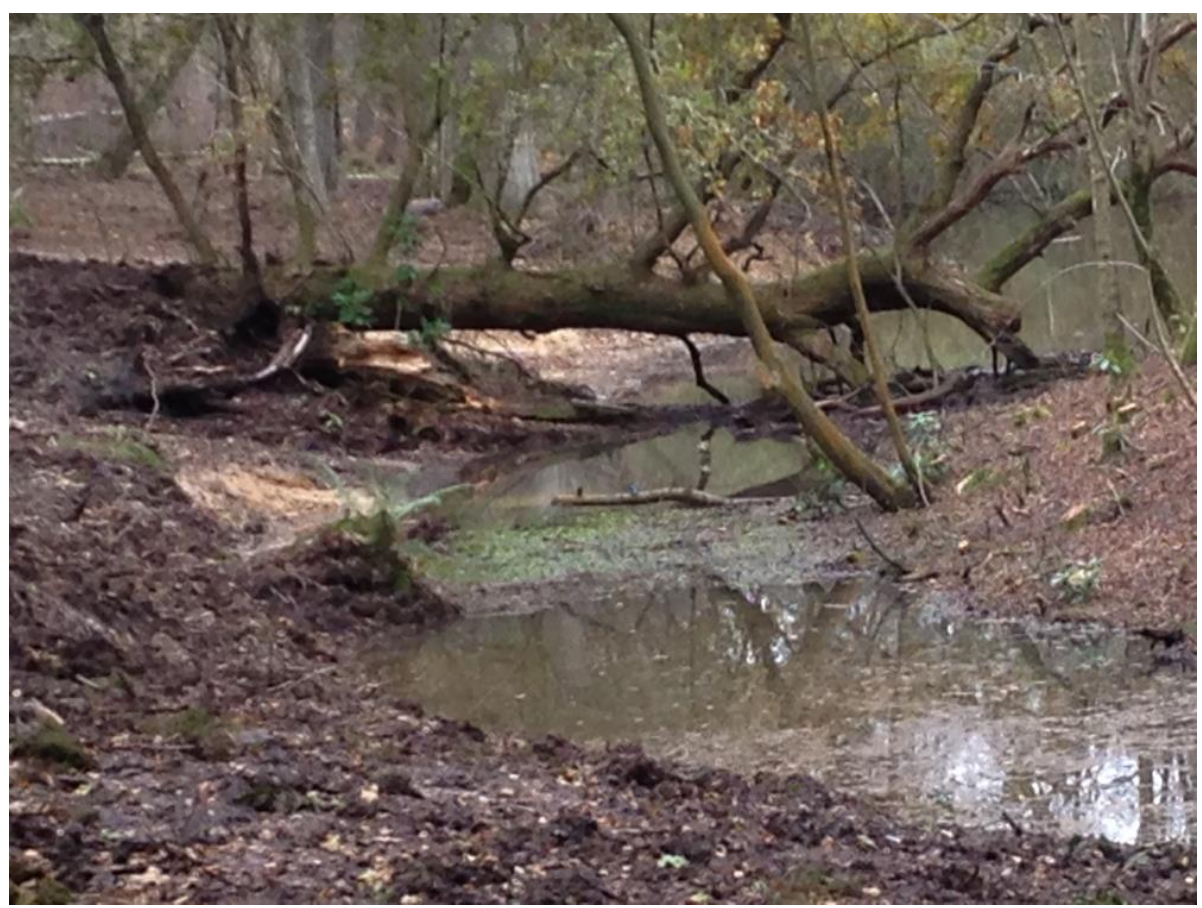

Figure 1 Photograph by Joe D., 2014

place that affords him the opportunity to take images of animals on his iPhone.

In one of our meetings, Joe showed me a photograph (Figure 1) that he has taken on his iPhone. Unlike the close to medium shots that he showed me previously, this wide-angle depiction of a forest stood out, so I immediately asked: 'Why did you take this photo, Joe?' 'There are two kingfishers on the wood in the centre of the frame. They are there in the picture, some blue and orange specs'. Interested in his specific viewpoint, I had to zoom in and still found it difficult to recognise the two birds. What I saw was a landscape photograph of a forest that I would have readily identified as the motivation of taking that picture. It was, however, not Joe's inspiration; he was not interested in capturing the bigger scene of the forest.

A discussion revealed that it was strictly the pair of kingfishers that had caught Joe's eye, and that he wanted to photograph in that particular moment. Yet, despite 'zooming in a little', he was too far away to capture them closer. Nevertheless, this image had its own logic and Joe's understanding of how to relate to the birds (Grandin 2006). To him, it was 'the clearest picture without disturbing them'. I was intrigued to know what else, aside from the birds, Joe would see in this picture. His response was:

All my eye focused is on that specific area in that photo. It's not really that I'd think about anything around that day, just that specific time, that specific place, that specific sight, the specific shot of the photo. When you talk about a photograph, I think more about that image alone. Everything else is unimportant around the time of taking that photo. That's' what I see in the photos I take (personal interview, 15 December 2014). 
There was no doubt that the two kingfishers were the focus of Joe's viewpoint, which he wanted to capture photographically.

During our sessions, we went through many of his pictures, yet Joe never selected a particular sequence of images that he wanted to show me. With no special album created to categorise his images, Joe notes: 'I keep them in the order I take them' (Bogdashia 2003). As a consequence, Joe sometimes only showed me a few images, while other times he showed me a large number of images that he took at, for example, a fair. Other photographs in his camera roll depict, for example, frogs, owls, otters, badgers, but also pints of beer at a pub and some outdoor art installations that Joe saw on his visits to art galleries. His main object of interest, however, seems to be the animal world, of which he has many close to medium shots that represent a particular moment that he considers worthy of being photographed.

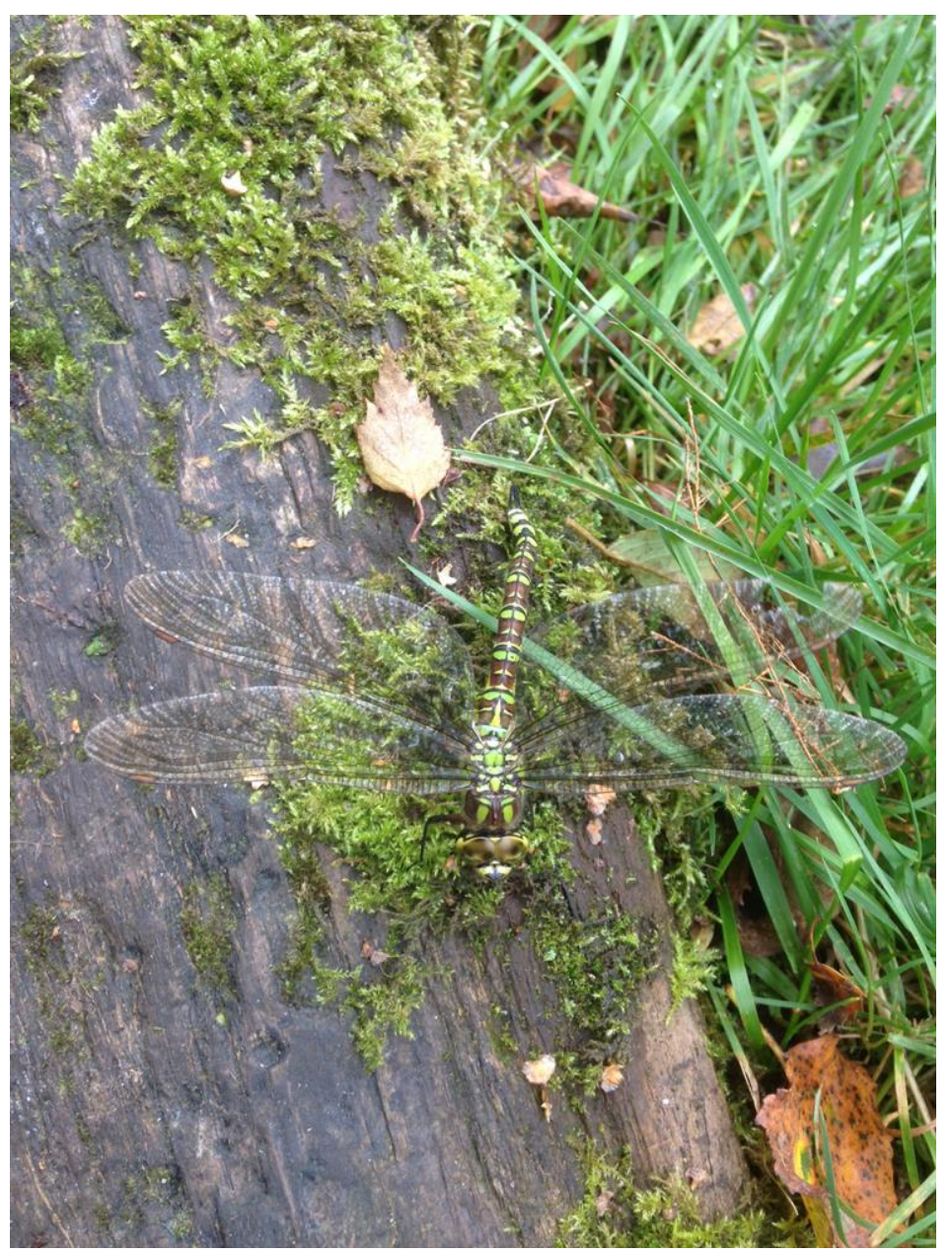

Figure 2 Photograph by Joe D., 2014

One time he showed me a close-up depiction of a dragonfly (Figure 2). In the process of capturing the insect in a few different versions, Joe 'avoided cutting off any wing tips [and] tried to get the right angle and right amount of shade and light'. He sounded pleased with the end result, telling me that he was asked to email the photograph to his manager at the countryside centre, who would print and use it for educational 
purposes. 'The photo will be a great addition'. In a similar conversation on capturing the moment and sharing it with others, Joe explains:

It's capturing what is most inspiring or significant for me of that moment, a scene of that moment that was worth taking a photo of, helping me to remember it, and share it with others. When I want to share a picture, I share it mostly in person, straight from the screen. I go to my iPhone and do it then (personal conversation, 17 November 2014).

The moment has been widely discussed in the literature of photography (CartierBresson 1994). I was, however, interested in exploring what the moment means to Joe, since he frequently mentions it in relation to his photography. In response to my question, he provides an important insight into his approach to his practice:

I just move into the position [from which] I want to take the picture in real life. I don't tweak with the phone, I just get into the right position to get the best image of the object in question. It's about the presence of my life and capturing that presence (personal conversation, 17 November 2014).

This is a significant remark, suggesting that Joe aligns himself with the photographs he takes; he is aware of his body position and movement, and carefully approaches the animals he sees, in real life and through photography. That becomes clearer when he describes a frog image, maintaining that, 'it takes careful handling to pick up a frog'. It is through this observation that I thought the forest picture (Figure 1) stood out and appeared in isolation to the rest of his images. Joe, however, clearly stated his intention in our discussion, an important reminder of the strengths of participatory research (Aldridge 2007; Joanou 2009; Tinkler 2008; Yates 2010). Indeed, Joe's images are not merely taken with a seeming effortlessness and transparency; they have a meaning, value and often purpose attached to them. Asking Joe what motivates him to take photographs, he replies:

It all depends on what comes up, and whether I want to take a photo or not. There is nothing planned or set. It depends on how reliable I think I feel. I don't want to ruin a shot, and it depends on how much time I have to take a photo that is worthy of being taken (personal conversation, 16 March 2015).

Joe's photography seems to be guided by his sensory perception, visuality, lived experience and interests, which helps him decide whether a moment is worthy of being photographed. Once he captures that moment, he retains his photographs in their originality; he does not enhance or manipulate his images in any way. It appears that the exposure of his iPhone camera at a particular moment in time makes an image what it is to Joe, 'an indexical sign of light, a moment, exposed, captured' (Drucker $2010,24)$. In other words, to Joe images appear to depict the truth that is in front of the lens, 'the absolute Particular' (Barthes 2000, 4). Moreover, Joe's autism appears to play an important role in his photography. Here, Olga Bogdashina explains that, 'autistic people seem to perceive everything as it is. It is sort of "literal perception", for example, they may see things without interpretation and understanding [...] autistic people look at the world the way it actually is' (2003, 45, italics in original). This emphasises that Joe's photographs are accurate representations of his world. 


\section{Feeling the Right Moment to take a Photo: Alex's photography ${ }^{2}$}

Alex was 18 at the time of his participation, and about to finish his A-levels with a focus on art and design. A very media-savvy young autistic male, Alex enjoys experimenting with photography and uses editing features and filters to manipulate his photographs. He mainly uses a small digital camera and often goes out with a deliberate and self-conscious intent to take photographs in suburban environments.

Alex appears to be guided by his feelings to photographically express the ways he sees the world, claiming that, 'I feel when it's the right moment to take a photo, as it feels much more natural that way'. Similar to Joe, Alex often mentions the moment in his photography; however, given his knowledge of the medium, the photographic moment for Alex does not seem to be merely 'an image of a single snapshot within a continuum' (Drucker 2010, 22), but rather becomes and event (Jay 2009). Indeed, Alex is an image-maker. For the purpose of conceptualising his ideas and developing his technical photography skills, Alex goes out to take images that fit in and around ideas he aims to depict photographically. As a habit, he annotates and analyses them, claiming that this procedure helps him remember 'what I thought when I captured a particular moment'.

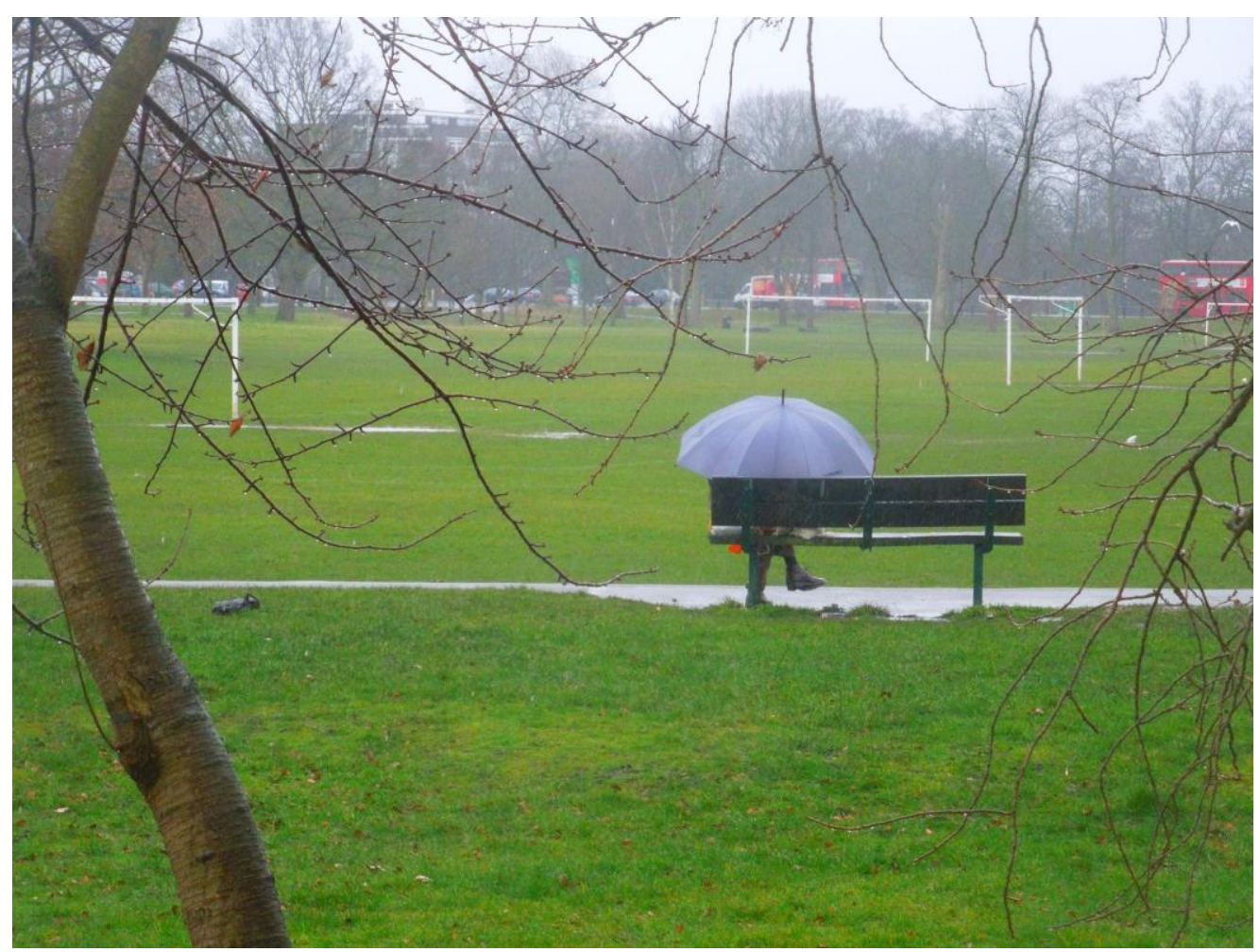

Figure 3 Photograph by Alex S., 2015

Alex showed me a sequence of thirteen photographs that he had selected, organised and saved in a separate album on his iPhone. Aiming to visually explore the idea of juxtaposing summer and winter, he explained that rather than showing all photographs that he took, he 'felt it was best to choose the best ones'.

\footnotetext{
${ }^{2}$ Subsequent quotes under this subheading are from the same research participant, Alex S., except where otherwise specified.
} 
Alex opened the sequence with a photograph depicting a person sitting on the bench (Figure 3) and explains it was not the person that caught his eye, but the way the branches were spread out in relation to the individual. Without prompting him, he explained his motivation for placing this particular image first in the series, maintaining that 'it has the best quality to it, not just in terms of looks but it almost has a narrative to it'. When I asked what he particularly liked about this image, Alex expressed enthusiasm, saying 'What is really cool is that the branches seem to be arching in towards her, they seem to almost encircle her'. While he took three different versions, he insisted that, 'this one works best because the atmosphere, the setting, feels a lot more open with the branches arching into her'.

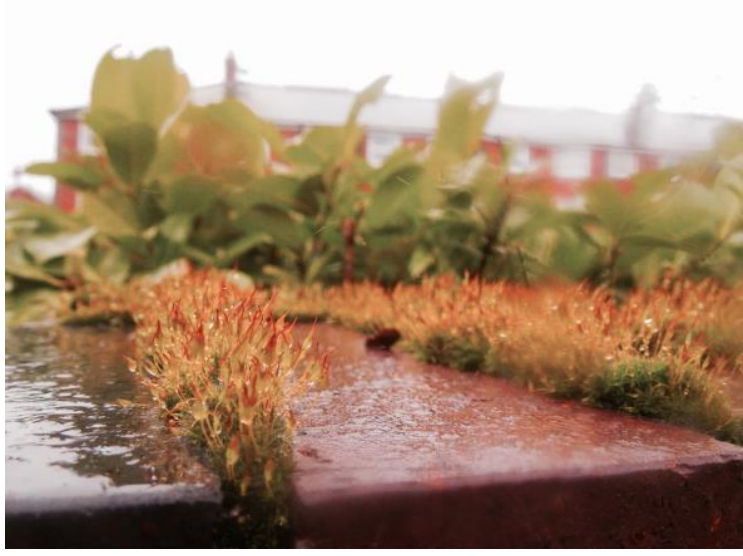

Figure 4 Photograph by Alex S., 2015

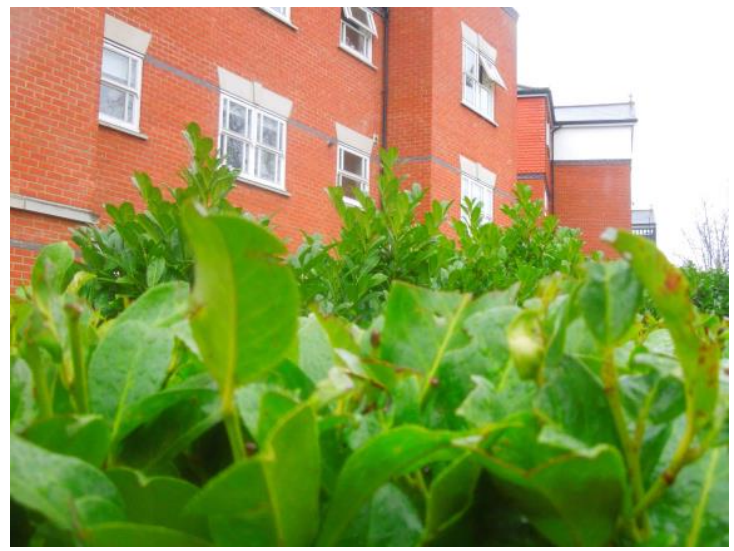

Figure 5 Photograph by Alex S., 2015

Drawing on his detailed vision and body position to experiment with different vantage points, depths of field and vibrant, contrasting colours, Alex depicts close-ups of grass (Figure 4), wet leaves (Figure 5) and close-up branch structures to depict summer, emphasising the rich textures of the details.

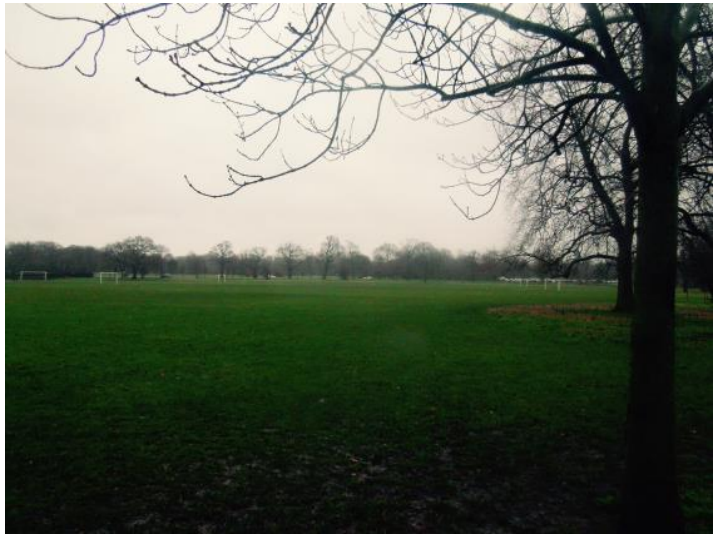

Figure 6 Photograph by Alex S., 2015

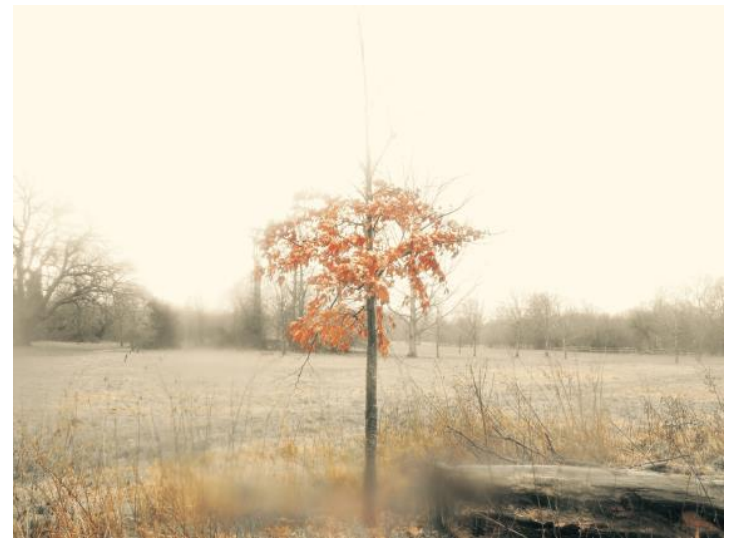

Figure 7 Photograph by Alex S., 2015 
Winter, on the other hand, is illustrated through wide-angle portrayals of empty parks (Figure 6), and individual trees in park scenes (Figure 7) to convey solitude, his metaphorical way to depict winter. It is noteworthy to highlight that compared to Joe, Alex provides detailed explanations of the technical settings and filters he uses to enhance his photographs and what he aims to convey. Bearing in mind the ability of autistic people to focus on details, technical features appear to be meaningful pieces of information for Alex in relation to his photography.

Alex reiterates the implication of his selection process, stating that the sequence starts with a strong photograph, followed by a 'dip in the middle' before 'ending in isolation'. Using his sensory perception to capture his photographs, Alex offers his insights into how photography mediates his vision, and how the medium is capable of 'manipulating visual communication'. His series carries a visual narrative, telling the viewer something about his perception of how he visualises and constructs the world he sees and experiences. Moreover, rather than perceiving photographs as depictions of individual moments within a continuum of time, Alex appears to use his photographs to illustrate a whole event. Here Bogdashina suggests,

Visual communication systems can take various forms - objects, photographs, pictures, drawing. These visuals make it easier [...] for autistic children to orient in the world around them but also to comprehend such concepts as time, sequence of events and abstract notions $(2005,222)$.

Alex's approach to photography appears to be conceptual, enabling him to use vision and proprioception in a way that affords him to focus on both the detail and the whole scene at a conceptual level, as illustrated in his contrast of summer and winter.

The short vignettes of Joe and Alex intended to offer insights into their photographic practices. By taking this route, I attempted to illustrate that two autistic individuals appear to approach and understand photography in their own ways to depict their vision and perceptions of their everyday lives. That is partly facilitated by their different technical levels, understanding and enthusiasm for the medium, and partly by the wide spectrum of autistic subjectivity and agency, which may include lack of social and communication skills. While Joe and Alex appear to rely on their sensory modalities, they reinforce the notion that 'no two autistic people appear to have the exact same patterns of sensory perceptual experiences' (Bogdashina 2003, 45).

Part III discusses theories that underpin this study, including phenomenology and embodiment in relation to photography and the idea of 'being-in-the-world'. The discourses derive from a broad number of academic fields, an inevitable approach to my investigation, as both areas of photography and autism have been critically discussed across several disciplines.

\section{A Phenomenological Approach to Seeing Autistic People's Photographs}

Photographs invite people to look, and it is no different with Joe and Alex's images. However, to better understand their photography, this study draws on the literature on phenomenology and embodiment. 
In his attempt to raise the issue of Being and Being-in-the-world, Martin Heidegger broke with Husserl and the Cartesian tradition by replacing epistemological questions with ontological ones to highlight that being is 'to be there', and 'there' is the world (Dreyfus 1991). Heidegger calls this 'fundamental way of making sense of things our understanding of being', and argues that 'we do not know - that is not a representation in the mind corresponding to the world - but that we simply are' (Dreyfus 1991, italics in original). His approach underlines that the world is everywhere around us, reinforcing that the notion of being-in-the-world needs to be seen as a whole entity, as 'the possibility of seeing the world as a world, of re-collecting and re-membering the question of Being' (Smith et al. 2009, 28-29). Engaging with the senses is central to experiencing the world, and as Mick Smith and his colleagues argue,

[S]ight, the most paradigmatically detached, distanced and objective of the senses, affects us intimately, magically expressing something of our mode of being-in-the-world and providing insights into others (ibid., 10).

This is true for Joe and Alex. Discussions with them reveal that they use vision to photograph moments of their everyday lives, yet, they also rely on other sensory perceptions. Recounting the moment before creating the photograph (Figure 3), for example, Alex explained that he was conscious about being noticed by the person on the bench. He used his sight to watch her, but was aware of his body position and movement in relation to the person, which enabled him to carry on without being noticed. Similarly, Joe's comment of the kingfishers (Figure 1) disclosed that while he saw them from afar, he only 'zoomed in a little to get the clearest picture without disturbing them'. Considering the triad of impairments in autism, in combination with the kinaesthetic sense of spatial awareness, little and careful zooming suggests Joe's distanced gaze of the birds and the physical environment of the forest. Hence, it is not only vision that is important for their photography, but other sensory perceptions too.

Mikhail Bakhtin (1993) proposes to integrate vision into a non-hierarchical and openended perceptual regime that involves not just actual bodily senses but metaphorical extensions of these into a diversity of human domains and endeavours. With his core theory rooted in a broad idea of embodiment, which seeks to embrace all sensory modalities, Bakhtin argues that these endeavours relate to a key condition of human beings that we experience when encountering an external world, in which we are literally thrown into, that consists of events and objects, with which we are confronted and that demand responses. In his own words, Bakhtin explains:

[T]his world-as-event is not just a world of being, of that which is given: no object, no relation, is given here as something simply given...but is always given in conjunction with another given that is connected with those objects and relations $(1993,32)$.

Bakhtin's remark implies that people encounter their environments simultaneously with all their senses and their physical body. This experience is not enforced; the active involvement of the body has potential agency to participate or resist in any activity (Noland 2009). Indeed, the body is not merely completing a certain task, such as photography, but measuring space, movement, monitoring fraction and pressure, as well as adjusting movements of weight. In other words, the kinaesthetic experience 'affects the gestures that are made and the meanings they convey' (Noland 2009, 2). 
This complexity is represented in Joe and Alex's photography - not through their photographs alone but in collaboration with their descriptions.

Similarly drawing on the senses, Maurice Merleau-Ponty (1962) argues that feelings are essential in how individuals perceive the world, yet offers an alternative account of feelings. For Merleau-Ponty,

Feelings are aspects of how the world is perceived. On his account, perception has an affective dimension - a dog can look scary [...] an old church can appear foreboding. [...] Merleau-Ponty claims feelings infuse the content of perception, and are not separable from it (Romdenh-Romluc 2011, 175).

In his approach to phenomenology, Merleau-Ponty understands the term as a way of describing the nature of people's perception of the world; phenomenology offers an explanation of human sensory experience. In Merleau-Ponty's own terms:

First of all, it is clear that we can distinguish in ourselves between "true" feelings and "false" feelings; from this fact it is clear that everything we sense in ourselves is not found on the same plane of existence or true in the same way and that there are degrees of reality in us, just as outside of us there are "reflections", "phantoms", and "things" (1962, 437).

Perception is therefore the background of experience, which may be reflective or unreflective. Merleau-Ponty argues that, '[a]n initial perception independent of any background is inconceivable. Every perception presupposes [...] a certain past' (1962, 281). He indicates that the notion of feelings is complex and includes facets and perceptions of diverse realities inside and outside the body, further suggesting that 'perception is precisely the way in which it makes manifest a world by carving out a concrete perspective in the recesses of the body' (1962, X, Forward). Therefore, by offering his accounts of feelings and perception, Merleau-Ponty argues that the body is not only a biological or physical unit, but an entity with feelings that structures one's situation and experience within the world and how it is perceived. In other words, this perception has an affective dimension, with individuals experiencing moments and situations in their own subjective ways.

With this in mind, phenomenology facilitates an understanding of how young autistic people embody visuality, and use the medium to express their ways of being-in-theworld. By grounding their sensory perception into their experienced and experiencing body, autistic people make their presence felt through their entry into the domain of photography. In the process of their photography, their body appears to accomplish the task of photography, however, 'it is simultaneously measuring space, monitoring pressure and friction, accommodating shifts of weight. These kinaesthetic experiences that exceed communicative or instrumental projects affect the gestures that are made and the meanings they convey' (Noland 2009, 2). In other words, people are embodied in their environments, existing in a particular time and place, which is experienced by no other person in exactly the same way. 


\section{Conclusion}

As this paper aimed to suggest, the two young autistic participants appear to use their sensory perception of vision, their kinesthetic experience and proprioceptive awareness to approach and understand photography in their own ways. Whether they photograph animals, sharp details or empty parks, their particular way enables them to visually express moments and feelings of their everyday lives. Photography seems to be the tool for accessing and taking a reflective stance towards themselves in the world, enabling them to visually communicate their lived experiences. Moreover, they align themselves to their objects and environment by drawing on subjective multisensory experiences and embodiment.

With that in mind, it is phenomenology and embodiment that help understand the photographic practices of autistic participants. While it is not possible to read people's embodied seeing and visual experience straight off the photographs, phenomenology provides a productive way of thinking about and understanding participants' photography as a way of being-in-the-world.

The advantages and strengths of a multi-method and multimodal approach that this study employed generated insights into participants' visuality, perception and distinct ways of seeing. Moreover, the methods encouraged reflexivity in the research process, and helped develop a more profound understanding of contemporary visual culture, photography and autism.

As this study progresses, further approaches and theories will be considered, including metonymy to understand participants' verbal and written accounts of their photographs. However, the question remains how the different approaches relate together in order to develop an analytical framework for this study that holds the individual approaches together.

\section{References}

Aldridge, J. (2007) 'Picture this: The use of Participatory Photographic Research Methods with People with Learning Disabilities, Disability and Society, 22 (1), 1-17

Attwood, T. (2007) The Complete Guide to Asperger's Syndrome, London and Philadelphia: Jessica Kingsley Publishers

Bakhtin, M. (1993) Toward a Philosophy of the Act, Austin, TX: University of Texas Press

Barthes, R. (2000 [1980]) Camera Lucida: Reflections on Photography. London: Vintage.

Berger, J. (1972) Ways of Seeing, London: Penguin Books 
Bogdashina, O. (2003) Sensory Perceptual Issues in Autism and Asperger Syndrome: Different Sensory Experiences, Different Perceptual Worlds, London and Philadelphia: Jessica Kingsley Publishers

Bogdashina, O. (2005) Communication Issues in Autism and Asperger Syndrome: Do We Speak the Same Language?, London and Philadelphia: Jessica Kingsley Publishers

Boucher, J. (2009) The Autism Spectrum: Characteristics, Causes and Practical Issues, London and Thousand Oaks: Sage

Cartier-Bresson, H. (1994) 'Still living for the moment', in C. Lury (2004) Prosthetic Culture: Photography, Memory and Identity, London and New York: Routledge

Clark-Ibanez (2007) 'Inner-City Children in Sharper Focus: Sociology of Childhood and Photo-elicitation interviews', in G. Stanczak (ed.) Visual Research Methods: Image, Society and Representation, London and Thousand Oaks: Sage, pp. 167-196

Davidson, J. (2008) 'Autistic culture online: Virtual communication and cultural expression on the spectrum', Social \& Cultural Geography 9 (7), 791-806

Dreyfus, H. (1991) Being-in-the-World: A Commentary on Heidegger's Being and Time, The MIT Press: Cambridge.

Drucker, J. (2010) 'Temporal Photography', Philosophy of Photography 1 (1), $22-28$

Frosh, P. (2003) The Image Factory: Consumer Culture, Photography and the Visual Content Industry, Oxford and New York: Berg

Garner, I. and Hamilton, D. (2001) 'Evidence for Central Coherence: Children with Autism Experience Visual Illusions', in J. Richer and S. Coates (eds) Autism: The Search for Coherence, London and Philadelphia: Jessica Kingsley Publishers

Grandin, T. (2006) Thinking in Pictures: And Other Reports from my Life with Autism, London: Bloomsbury

Guillemin, M. and Drew, S. (2010) 'Questions of Process in ParticipantGenerated Visual Methodologies', Visual Studies 25(2), 175-188.

Hand, M. (2012) Ubiquitous Photography, Cambridge: Polity Press

Haraway, D. (1991) Simians, Cyborgs, and Women: The Reinvention of Nature, New York: Routledge

Harper, D. (2002) 'Talking about Pictures: A Case for Photo Elicitation', Visual Studies, 17 (1), 13-26 
Heidegger, M. (1962) Being and Time, Harper and Row: New York.

Jay, M. (2009) 'Photography and the Event', in Shevchenko, O. (ed.) Double Exposure: Memory and Photography, New Brunswick and London: Transaction Publishers

Joanou, J. P. (2009) 'The Bad and the Ugly: Ethical Concerns in Participatory Photographic Methods with Children Living and Working on the Streets of Lima, Peru', Visual Studies, 24 (3), 214-223

Josephides, L. (1997) Representing the anthropologist's predicament, in: James, A. Hockey, J. and Dawson, A. (eds.) After Writing Culture: Epistemology and praxis in contemporary anthropology. London and New York: Routledge

Larsen, J. and Sandbye, M. (2014) Digital Snaps: The New Face of Photography, London: I.B. Tauris

Lee, D-H. (2010) 'Digital Cameras, Personal Photography and the Reconfiguration of Spatial Experiences', The Information Society, 26 (4), 266-275

Merleau-Ponty, M. (1962) Phenomenology of Perception, London and New York: Routledge

Mitchell, C. (2011) Doing Visual Research. London and Thousand Oaks, CA: Sage

Noland, C. (2009) Agency and Embodiment: Performing Gestures/Producing Culture, Massachusetts: Harvard University Press

Packard, J. (2008) 'I'm Gonna Show You What It's Really Like Out There: The Power and Limitation of Participatory Visual Methods', Visual Studies, 23 (1), 63-76

Pink, S. (2009) Doing Sensory Ethnography, London and Thousand Oaks, CA: Sage

Pink, S. (2013) Doing Visual Ethnography, $3^{\text {rd }}$ edn, London and Thousand Oaks, CA: Sage

Prosser, J. (2011) 'Visual Methodologies: Towards a more Seeing Research', in N.K.Denzin and Y.S. Lincoln (eds.) The Sage Handbook of Qualitative Research, $2^{\text {nd }}$ edition, London and Thousand Oaks: Sage, pp. 479-496

Romdenh-Romluc, K. (2011) Merleau-Ponty and Phenomenology of Perception, London and New York: Routledge 
Rose, G. (2012) Visual Methodologies: An Introduction to Researching with Visual Materials ( $3^{\text {rd }}$ edition), London and Thousand Oaks: Sage

Schwartz, D. (2007) 'If a Picture is Worth a Thousand Words, Why are You Reading this Essay?' Social Psychology Quarterly, 70 (4), 319-321

Smith, M., Davidson, J., Cameron, L. and Bondi, L. (eds.) (2009) Emotion, Place and Culture, Farnham: Ashgate

Sontag, S. (1977) On Photography, New York: Penguin

Tinkler, P. (2008) 'A Fragmented Picture: Reflections on the Photographic Practices of young people', Visual Studies 23(3), 255-266

Yates, L. (2010) The story they want to tell you, and the visual story as evidence: Young people, research authority and research purposes in the education and health domains, Visual Studies 25(3) 280-291

Uschi Klein is a $\mathrm{PhD}$ student at the University of Brighton.

Email: U.Klein@ brighton.ac.uk 